\title{
PUBLIC SCHOOL ACCESS OR STAY-AT-HOME PARTNER: FACTORS MITIGATING THE ADVERSE EFFECTS OF THE COVID-19 PANDEMIC ON ACADEMIC PARENTS
}

\author{
Tatyana Deryugina \\ Olga Shurchkov \\ Jenna E. Stearns \\ Working Paper 29668 \\ http://www.nber.org/papers/w29668 \\ NATIONAL BUREAU OF ECONOMIC RESEARCH \\ 1050 Massachusetts Avenue \\ Cambridge, MA 02138 \\ January 2022
}

We gratefully acknowledge helpful feedback from Alicia Sasser-Modestino and participants in the Loyola Marymount University Economics Department Seminar, the Gender Research Group Seminar at SOFI, Stockholm University, and the session "Gendered Impacts of the COVID-19 Pandemic" at the 2022 ASSA meetings. Anushka Kelishkar provided excellent research assistance. All remaining errors are our own. The views expressed herein are those of the authors and do not necessarily reflect the views of the National Bureau of Economic Research.

NBER working papers are circulated for discussion and comment purposes. They have not been peer-reviewed or been subject to the review by the NBER Board of Directors that accompanies official NBER publications.

(C) 2022 by Tatyana Deryugina, Olga Shurchkov, and Jenna E. Stearns. All rights reserved. Short sections of text, not to exceed two paragraphs, may be quoted without explicit permission provided that full credit, including $(\odot$ notice, is given to the source. 
Public School Access or Stay-at-Home Partner: Factors Mitigating the Adverse Effects of the COVID-19 Pandemic on Academic Parents

Tatyana Deryugina, Olga Shurchkov, and Jenna E. Stearns

NBER Working Paper No. 29668

January 2022

JEL No. J13,J16,J22

\section{ABSTRACT}

The COVID-19 pandemic created unexpected and prolonged disruptions to childcare access. Using survey evidence on time use by academic researchers before and after the pandemic, we analyze the extent to which greater access to either school-based or partner-provided childcare mitigated the severe disruptions to research observed among parents during COVID-19. We find that access to public schools offset the research time loss to a greater extent among mothers of young children relative to fathers, narrowing the emerging post-pandemic gender gap. Having a stay-at-home partner reduced the disruptions to research time equally for both genders.

Tatyana Deryugina

Department of Finance

University of Illinois at Urbana-Champaign

515 East Gregory Drive, MC-520

Champaign, IL 61820

and NBER

deryugin@illinois.edu

Olga Shurchkov

Department of Economics

Wellesley College

106 Central St.

Wellesley, MA 02481

oshurchk@wellesley.edu
Jenna E. Stearns

Department of Economics

University of California, Davis

One Shields Ave

Davis, CA 95616

jestearns@ucdavis.edu 


\title{
Public School Access or Stay-at-Home Partner: Factors Mitigating the Adverse Effects of the COVID-19 Pandemic on Academic Parents
}

\author{
By Tatyana Deryugina, Olga SHurchKov, and JenNa Stearns*
}

\begin{abstract}
The COVID-19 pandemic created unexpected and prolonged disruptions to childcare access. Using survey evidence on time use by academic researchers before and after the pandemic, we analyze the extent to which greater access to either school-based or partner-provided childcare mitigated the severe disruptions to research observed among parents during COVID-19. We find that access to public schools offset the research time loss to a greater extent among mothers of young children relative to fathers, narrowing the emerging post-pandemic gender gap. Having a stay-at-home partner reduced the disruptions to research time equally for both genders.
\end{abstract}

The COVID-19 pandemic created unexpected and prolonged disruptions to childcare access around the world, contributing to a worldwide "shecession" (Alon et al 2020). Surveys that focus on academics reveal that these disruptions disproportionately reduced research time for mothers of young children relative to fathers, and this loss of research time was accompanied by an increased burden of childcare and other household duties (Myers et al. 2020; Deryugina et al. 2021; Shallaby et al. 2021). ${ }^{1}$

Using survey evidence on time use by academic researchers before and after the disruptions caused by COVID-19, we analyze the extent to which greater access to either school-based or partner-provided childcare mitigated the severe disruptions to research time observed among parents of young children during COVID-19.

\footnotetext{
Deryugina: University of Illinois, Urbana-Champaign, 4050 Business Instructional Facility, 515 Gregory Drive, Champaign, IL 61820 (email: deryugin@illinois.edu); Stearns: UC Davis, 1114 SSH, 1 Shields Avenue, Davis, CA 95616 (e-mail: jestearns@ucdavis.edu); Shurchkov: Wellesley College, 106 Central St., Wellesley, MA, 02481 (email: olga.shurchkov@wellesley.edu). We gratefully acknowledge helpful feedback from Alicia Sasser-Modestino, and participants in the Loyola Marymount University Economics Department Seminar, the Gender Research Group Seminar at SOFI, Stockholm University, and the session "Gendered Impacts of the COVID-19 Pandemic" at the 2022 ASSA meetings. Anushka Kelishkar provided excellent research assistance. All remaining errors are our own.

1 The gendered effects of the pandemic on research productivity, as measured by submissions to pre-print series and journals, are less wellestablished. Research productivity seems to have declined by a greater margin for women, according to self-reports (Barber et al. 2021; Staniscuaski et al. 2021) and evidence from economics working paper series submissions over the first few months of the pandemic (Squazzoni et al. 2021; Amano-Patiño et al. 2020; Cui et al. 2021). Longer-term impacts of the pandemic on academic productivity have not yet been established. Gao et al. (2021) find that significantly fewer new projects were started in 2020 relative to 2019, suggesting declines in future productivity.
} 
We estimate that schools being open the entire time between February 16 and July 31, 2020 would have mitigated essentially the entire drop in research time that women with young children experienced during the early period of COVID disruptions. Changes in fathers' research time are smaller on average and uncorrelated with school openness. Having a stay-at-home partner offset the lost research time equally for mothers and fathers, although on average mothers with a stay-athome partner experienced a larger drop in research time than fathers with a stay-at-home partner did. Both school openness and the presence of a stay-at-home partner reduced the post-COVID increases in time spent on childcare. But because mothers experienced a disproportionate increase in childcare time, these offsetting factors did not eliminate the gender gap in the childcare burden.

\section{Data Sources and Sample}

The data for this study come from two sources. First, we sent an email survey to approximately 900,000 individuals who had published at least one academic article from 2015-2019. The distribution window, including two follow-up reminders, ran from May 27, 2020 to July 21, 2020, yielding a total of 27,991 responses. Detailed information about the survey is provided in the online appendix of Deryugina et al. (2021).

The main question of interest asked the respondents to estimate, both before and after the start of the COVID-19 disruptions, the average number of hours in a given workday they spent on research, all other job-related activities, childcare, commuting to and from work, housework, sleep, and all other activities. Respondents with spouses/partners were asked to provide the same time use information for their partner. Instead of separately asking about research and other work time, however, we simply asked about the total time partners spent in paid work. Our main explanatory variables are gender and the number and ages of child dependents, but we also collected information on other life circumstances (such as the presence of elderly dependents and marital status) and professional circumstances (PhD year, research area(s), academic rank, resources required for research success, such as equipment or access to human subjects, and basic demographics).

We focus on survey respondents with doctoral degrees who self-identified as either male or female and whose time-use answers add up to 24 hours per day. Because Deryugina et al. (2021) find that the decline in research time was overwhelmingly concentrated among parents of younger children, we further restrict the sample to respondents whose youngest child is under 12 years of 
age and lives with them. For our analysis of partner's employment status, we focus on respondents who live with a partner and provided estimates of their partner's working hours. This restriction yields a sample of 5,553 respondents: 3,125 men and 2,428 women.

For the school openness analysis, we instead restrict our sample to parents of children under 12 for whom we can identify country of residence. This information was available when the respondent's email had a country-specific domain extension. This sample consists of 5,773 respondents, with about 39 percent coming from the US, 36 percent from the European Economic Area (EEA), and 25 percent from the rest of the world.

Our second data source is the Global Monitoring of School Closures caused by the COVID-19 Pandemic Dashboard publicly available at the UNESCO Institute for Statistics. The dashboard provides daily information on COVID-related school closures for most countries in the world. For each country, we construct a school openness measure defined as the average fraction of days from February 16 to July 31, 2020, when primary schools were not fully closed (due to the pandemic or an academic break) at the national level. ${ }^{2}$

There is substantial heterogeneity in school openness over the survey window. Some countries with a significant number of respondents, such as Sweden, had primary schools open nearly 80 percent of the time (closed only for academic breaks), while other countries, such as Italy and Canada, were open only about 20 percent of this period. Online appendix Table A.1 provides the full list of countries in our sample, response rates, and the associated school openness fraction.

\section{Mitigating the Gendered Impact of COVID-19 on Research Time Use}

Using the same survey data, Deryugina et al. (2021) document that COVID-19 disruptions caused a decline in research time among academic parents of young children (under 12), mirrored by an increase in time spent on childcare and other housework. These effects were larger for mothers than fathers. Using a difference-in-differences approach, we estimate whether having a stay-at-home partner or access to external childcare-proxied by public school openness at the country level—helped to close these gaps.

\footnotetext{
2 We cross-check the UNESCO data with other publicly available sources to confirm accuracy. For the US, we added non-academic breakrelated closures listed in the Center for Global Development database. Results excluding the US are similar and can be found in the online appendix. See appendix Section A for details on openness data. It is challenging to correctly account for heterogeneity in partial school closures within different countries. We therefore construct our measure using full closure information only. Thus, in some cases, we are likely overestimating school openness. We leave the analysis of within-country variation in school openness to future research (see for example Fukumoto et al. 2021 for the case of Japan).
} 
Equation (1) captures the post-pandemic changes in time use for female academics relative to male academics, decomposing the effects of the pandemic by each potential mitigating factor (presence of a stay-at-home partner or school openness):

(1) $\Delta$ TimeUse $_{i}=\beta_{1}$ Female $_{i}++\beta_{2}$ Factor $_{i}+\beta_{12}\left[\text { Female }_{\text {Fetor }}\right]_{i}+X_{i}^{\prime} \gamma+\sigma_{t}+\varepsilon_{i}$,

where $i$ indexes individual respondents.

The $\Delta$ TimeUse $_{i}$ variables represent the difference in hours spent on a given activity pre- and post-COVID-19 (a negative value signifies a drop in hours since the pandemic). Female $e_{i}$ is an indicator of a respondent being female.

The variable Factor $_{i}$ is either: (1) an indicator equal to 1 if the respondent indicated that their partner worked zero hours in paid employment on a typical workday prior to the pandemic and 0 otherwise (HomePartner $)^{3}$ or (2) the fraction of days primary schools were not fully closed during the period of February 16-July 31, 2020 (Openness $_{i}$ ). Female $\times$ Factor $_{i}$ interacts the respondent's gender and the mitigating factor.

The vector $X_{i}$ is a set of respondent characteristics that includes year-of-PhD fixed effects. Finally, $\sigma_{t}$ represents survey completion date fixed effects.

We hypothesize that $\beta_{2}$ will be positive for research time and negative for childcare time, indicating that more childcare access alleviates some of the COVID-19 disruptions for parents, while $\beta_{12}$ will be positive for research time and negative for childcare time use if mothers disproportionately benefit from a given childcare option relative to fathers.

\section{Main Results}

\section{A. Effect of Having a Stay-at-Home Partner}

Figure 1 shows that prior to COVID-19, women's partners spent more hours than men's partners in paid employment and spent less time on childcare and other household duties.

\footnotetext{
${ }^{3}$ We take this approach rather than using the continuous measure for hours in paid employment because of concern about the cognitive load of accurately estimating time use for another person. There is also evidence that men and women have different perceptions about who does more at home (Pew Research 2021), which may lead to biased estimates of partner's time use in general. This is not the case only for a simple "not working at all” category. Results are similar if we define home partner based on post-COVID employment and if we include partners who worked less than three hours on average (see Tables C.1 and C.2 in the online appendix)
} 
In our sample, about 21 percent of men and 5 percent of women had a stay-at-home partner preCOVID-19 (that is, reported a partner with zero hours spent in paid employment). The pandemic increased the likelihood of one's partner working zero hours in paid employment by about 7 pp for men and $4 \mathrm{pp}$ for women (t-test p-value < 0.001; see online appendix Table A.2).

Table 1 presents estimates of Equation (1) for the change in research, childcare, and housework time by gender and partner status. Appendix Table B.1 shows estimates for other time use variables.

FIGURE 1. MEAN NUMBER OF HOURS PARTNERS OF RESPONDENTS SPENT ON EACH ACTIVITY BEFORE COVID-19 BY GENDER OF RESPONDENT

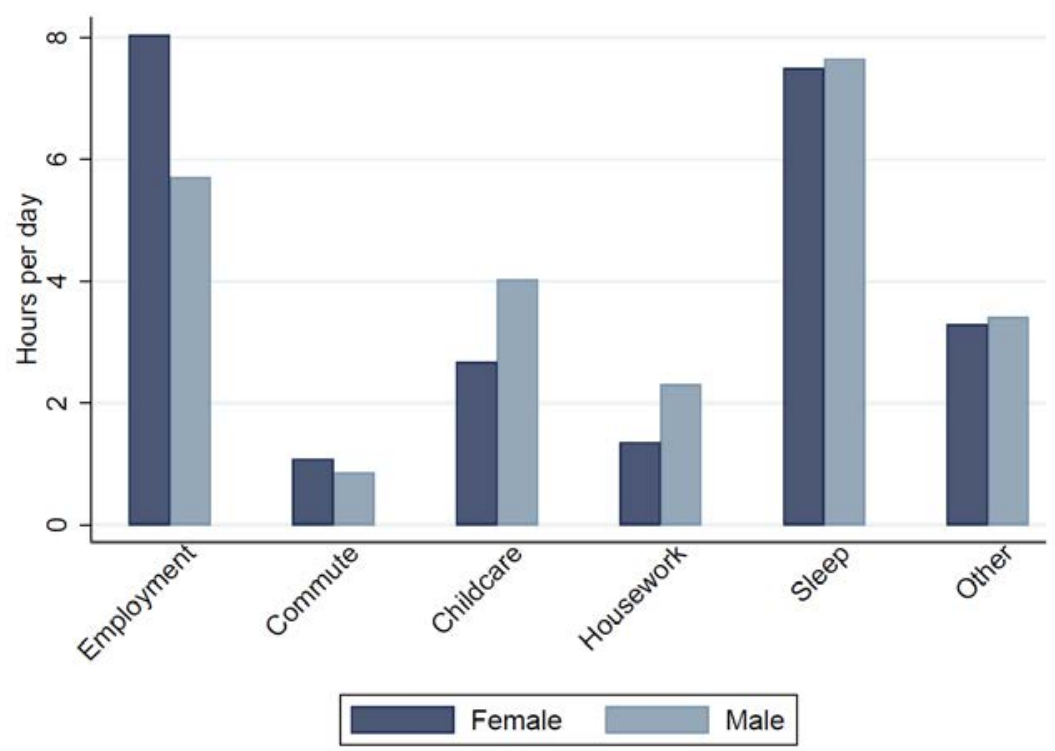

Note: All differences by gender are statistically significant at the 1 percent confidence level, except for "Other" ( $\mathrm{p}=0.086)$.

Relative to the pre-pandemic average, we find that both fathers and mothers benefit equally from having a stay-at-home partner when it comes to reducing the COVID research impact (Column 1). However, because mothers experience a larger drop in research time on average, a stay-at-home partner does not fully eliminate the gender gap in research time losses between men and women. A similar pattern emerges for increases in time spent on childcare (Column 2). Column 3 shows that mothers experience a lower post-COVID increase in housework when their partner stays home. Fathers' changes in housework are uncorrelated with having a stay-at-home partner.

Notably, defining a stay-at-home partner based on post-COVID employment yields a larger increase in childcare time among women with a stay-at-home partner compared to men with a 
stay-at-home partner (online appendix Table C.1). This difference in results could be due to men's partners being more likely to quit paid employment post-COVID specifically to take on the increased childcare burden.

Table 1 -Effects of Having a Stay at Home Partner on the Change in Time Use by Gender
\begin{tabular}{lccc}
\hline Variable & $\Delta$ Research & $\Delta$ Childcare & $\Delta$ Housework \\
\cline { 2 - 4 } & $(1)$ & $(2)$ & $(3)$ \\
\hline Female & $-0.425^{* * *}$ & $0.720^{* * *}$ & $0.124 * * *$ \\
& $(0.0582)$ & $(0.0609)$ & $(0.0286)$ \\
Home Partner & $0.465^{* * *}$ & $-0.927 * * *$ & -0.0443 \\
& $(0.0954)$ & $(0.0805)$ & $(0.0420)$ \\
Female + Home Partner & 0.224 & 0.200 & $-0.236 * *$ \\
& $(0.194)$ & $(0.189)$ & $(0.101)$ \\
\hline Dep. Var. Mean & -1.576 & 2.902 & 0.809 \\
R-squared & 0.0421 & 0.100 & 0.0253 \\
No. Observations & 5553 & 5553 & 5553 \\
\hline
\end{tabular}

Notes: Sample restricted to respondents with youngest child under 12 years of age in the household. Estimates from OLS regressions with controls for $\mathrm{PhD}$ year and date of survey completion FE. Significance levels: ${ }^{*} \mathrm{p}<0.10 ;{ }^{* *} \mathrm{p}<0.05 ; * * * \mathrm{p}<0.01$.

\section{B. Effect of Access to Primary Schools}

Table 2 shows estimates of Equation (1) for the extent to which primary schools in the respondent's country were partially or fully open in the early days of the pandemic.

Unlike having a stay-at-home partner, access to public school is associated with a significant increase in research time for mothers of young children relative to fathers (Column 1). The magnitude of the coefficient indicates that schools being fully open the entire time period would completely eliminate the gender gap in post-COVID changes in research time. For fathers, school openness is correlated with decreased childcare and housework, but has no effect on research time use. ${ }^{4}$ Interestingly, although on average mothers experience a larger increase in childcare time than fathers, mothers do not experience a significantly larger decrease in childcare time than fathers when schools are more open.

\footnotetext{
4 The results do not change if we exclude the US and are stronger if we restrict the sample to families with children under the age of 8 (see Appendix Tables C.4-C.5). Appendix Table C.5 shows that results are similar if the effects of a stay-at-home partner and school openness are estimated jointly.
} 
TABLE 2-EFFECTS OF PRIMARY SCHOOL OPENNESS ON THE CHANGE IN TIME USE BY GENDER

\begin{tabular}{|c|c|c|c|}
\hline \multirow[t]{2}{*}{ Variable } & \multirow{2}{*}{$\frac{\Delta \text { Research }}{(1)}$} & $\Delta$ Childcare & \multirow{2}{*}{$\frac{\Delta \text { Housework }}{(3)}$} \\
\hline & & $(2)$ & \\
\hline Female & $\begin{array}{c}-0.860^{* * *} \\
(0.154)\end{array}$ & $\begin{array}{c}0.888 * * * \\
(0.150)\end{array}$ & $\begin{array}{c}0.110 \\
(0.0742)\end{array}$ \\
\hline Openness & $\begin{array}{l}0.0131 \\
(0.221)\end{array}$ & $\begin{array}{c}-0.621^{* * *} \\
(0.206)\end{array}$ & $\begin{array}{c}-0.983^{* * *} \\
(0.102)\end{array}$ \\
\hline Female + Openness & $\begin{array}{c}0.828 * * \\
(0.326)\end{array}$ & $\begin{array}{l}-0.0112 \\
(0.332)\end{array}$ & $\begin{array}{l}0.0725 \\
(0.153)\end{array}$ \\
\hline Dep. Var. Mean & -1.587 & 2.927 & 0.801 \\
\hline R-squared & 0.0402 & 0.0823 & 0.0551 \\
\hline No. Observations & 5773 & 5773 & 5773 \\
\hline
\end{tabular}

Notes: Sample restricted to respondents with youngest child under 12 years of age in the household. Estimates from OLS regressions with controls $\mathrm{PhD}$ year and date of survey completion. Significance levels: ${ }^{*} \mathrm{p}<0.10 ;{ }^{* *} \mathrm{p}<0.05$; ${ }^{* * *} \mathrm{p}<0.01$.

\section{Discussion}

Our time-use survey reveals that the short-term adverse effects of the pandemic fell disproportionately on female academics with young children. In this paper, we show that mothers of young children benefit more than fathers from access to formal childcare. Informal childcare, proxied for by having a stay-at-home partner, reduces the disruptions to research time equally for both genders, but nonetheless leaves a gap between fathers and mothers. We leave it to future research to explore whether other family arrangements (grandparents watching the children) would lead to a different outcome. Furthermore, it would be interesting to investigate whether the gender of the partner makes a difference. Finally, school openness is potentially correlated with a variety of cultural factors that affect how women may have fared through the pandemic. 


\section{REFERENCES}

Alon, Titan, Doepke, Matthias, Olmstead-Rumsey, and Michele Tertilt. 2020. “The Impact of COVID-19 on Gender Equality” NBER Working Paper No. 26947.

Amano-Patiño, Noriko, Faraglia, Elisa, Giannitsarou, Chryssi, and Zeina Hasna. 2020. “The Unequal Effects of COVID-19 on Economists’ Research Productivity” Cambridge Working Papers in Economics: 2038.

Barber, Brad M., Jiang, Wei, Morse, Adair, Puri, Manju, Tookes, Heather, and Ingrid M. Werner. 2021. “What Explains Differences in Finance Research Productivity During the Pandemic?” The Journal of Finance 76(4): 1655-97.

Center for Global Development. 2020 - 2021. “COVID Education Policy Tracking” https://www.cgdev.org/media/covid-19-education-policy-tracker (accessed December 1, 2021)

Cui, Ruomeng, Ding, Hao, and Feng Zhu. 2021. “Gender Inequality in Research Productivity during the COVID-19 Pandemic,” Manufacturing \& Service Operations Management.

Deryugina, Tatyana, Shurchkov, Olga, and Jenna Stearns. 2021. "COVID-19 Disruptions Disproportionately Affect Female Academics,” AEA Papers \& Proceedings 111: 164-68.

Fukumoto, Kentaro, McClean, Charles T., and Kuninori Nakagawa. 2021. "No Causal Effect of School Closures in Japan on the Spread of COVID-19 in Spring 2020,” Nature Medicine, https://doi.org/10.1038/s41591-021-01571-8

Gao, Jian, Yin, Yian, Myers, Kyle R., Lakhani, Karim R., and Dashun Wang. 2021. "Loss of New Ideas: Potentially Long-lasting Effects of the Pandemic on Scientists," Nature Communications 12: 6188.

Myers, Kyle R., Tham, Wei Yang, Yin, Yian, Cohodes, Nina, Thursby, Jerry G., Thursby, Marie C., Schiffer, Peter, Walsh, Joseph T., Lakhani, Karim R., and Dashun Wang. 2020. "Unequal Effects of the COVID-19 Pandemic on Scientists,” Nature Human Behavior 4: 880-3.

Shalaby, Marwa, Allam, Nermin, and Gail J. Buttorff. 2021. "Leveling the Field: Gender Inequity in Academia during COVID-19,” PS: Political Science \& Politics 54 (4): 661-7.

Squazzoni, Flaminio, Bravo, Giangiacomo, Grimaldo, Francisco, Garcia-Costa, Daniel, Farjam, Mike, and Bahar Mehmani. 2021. "Only Second-Class Tickets for Women in the COVID-19 Race. A Study on Manuscript Submissions and Reviews in 2329 Elsevier Journals,” PLoS ONE 16(10): e0257919.

Staniscuaski, Fernanda, Kmetzsch, Livia, Soletti, Rossana C., Reichert, Fernanda, Zandonà, 
Eugenia, Ludwig, Zelia MC, Eliade F. Lima et al. 2021. “Gender, Race and Parenthood Impact Academic Productivity during the COVID-19 Pandemic: from Survey to Action,” Frontiers in Psychology 12: 1640.

UNESCO Institute for Statistics. 2020 - 2021. "COVID-19 Education Response" http://covid19.uis.unesco.org/global-monitoring-school-closures-covid19 (accessed December 1, 2021) 


\section{SUPPLEMENTARY ONLINE MATERIAL FOR \\ Public School Access or Stay-at-Home Partner: Factors Mitigating the Adverse Effects of the COVID-19 Pandemic on Academic Parents \\ By Tatyana Deryugina, Olga Shurchkov, and Jenna Stearns}

\section{Not for publication}

\section{Contents}

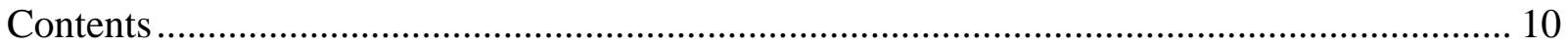

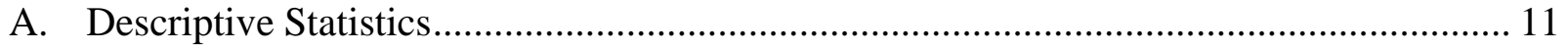

B. Analysis of Other Time Use Variables ........................................................................ 14

C. Additional Specifications and Robustness Checks ................................................................ 16 


\section{A. Descriptive Statistics}

Table A.1 shows the number of survey responses by country (ordered from largest to smallest) and provides the corresponding school openness measure, when available.

Table A.1: Response Rates and School Openness by Country

\begin{tabular}{|c|c|c|c|c|c|c|c|c|}
\hline Country & $\begin{array}{c}\text { Num. } \\
\text { Responses }\end{array}$ & $\begin{array}{c}\text { Percent } \\
\text { Open }\end{array}$ & & $\begin{array}{c}\text { Num. } \\
\text { Responses }\end{array}$ & $\begin{array}{c}\text { Percent } \\
\text { Open }\end{array}$ & & $\begin{array}{c}\text { Num. } \\
\text { Responses }\end{array}$ & $\begin{array}{c}\text { Percent } \\
\text { Open }\end{array}$ \\
\hline United States & 6,890 & $46.7 \%$ & Malaysia & 54 & $41.3 \%$ & Bosnia \& Herz. & 6 & $14.4 \%$ \\
\hline Italy & 1,172 & $13.8 \%$ & Hungary & 52 & $17.4 \%$ & Jamaica & 6 & $15.6 \%$ \\
\hline United Kingdom & 899 & $37.7 \%$ & Romania & 49 & $14.4 \%$ & Algeria & 5 & $15.0 \%$ \\
\hline Canada & 830 & $16.8 \%$ & Serbia & 42 & $17.4 \%$ & Latvia & 5 & $26.9 \%$ \\
\hline Germany & 762 & $53.3 \%$ & Hong Kong SAR & 39 & N/A & USSR & 5 & N/A \\
\hline Brazil & 756 & $22.8 \%$ & Slovenia & 39 & $45.5 \%$ & Venezuela & 5 & $17.4 \%$ \\
\hline Spain & 569 & $35.3 \%$ & Singapore & 34 & $67.1 \%$ & Brunei & 4 & $53.3 \%$ \\
\hline France & 443 & $47.9 \%$ & Croatia & 31 & $47.9 \%$ & Faroe Islands & 4 & $60.5 \%$ \\
\hline Australia & 442 & $90.4 \%$ & Pakistan & 29 & $16.2 \%$ & Morocco & 4 & $17.4 \%$ \\
\hline Netherlands & 338 & $48.5 \%$ & Nigeria & 28 & $23.4 \%$ & North Macedonia & 4 & $14.4 \%$ \\
\hline Sweden & 314 & $77.2 \%$ & Saudi Arabia & 27 & $13.2 \%$ & Qatar & 4 & $13.8 \%$ \\
\hline Japan & 302 & $79.0 \%$ & Slovak Republic & 21 & $35.3 \%$ & Uganda & 4 & $19.8 \%$ \\
\hline Mexico & 249 & $21.6 \%$ & Uruguay & 20 & $59.3 \%$ & Ethiopia & 3 & $16.2 \%$ \\
\hline China & 246 & $41.9 \%$ & Peru & 19 & $32.9 \%$ & Iraq & 3 & $12.0 \%$ \\
\hline India & 238 & $22.8 \%$ & Indonesia & 18 & $22.8 \%$ & Kuwait & 3 & $8.4 \%$ \\
\hline Switzerland & 229 & $47.9 \%$ & Estonia & 17 & $45.5 \%$ & Macao SAR & 3 & N/A \\
\hline Portugal & 220 & $41.3 \%$ & Thailand & 17 & $18.6 \%$ & Malawi & 3 & $32.3 \%$ \\
\hline Argentina & 218 & $17.4 \%$ & Egypt & 16 & $17.4 \%$ & Netherlands Ant. & 3 & N/A \\
\hline Chile & 199 & $35.9 \%$ & Luxembourg & 16 & $38.9 \%$ & Albania & 2 & $34.1 \%$ \\
\hline Austria & 184 & $57.5 \%$ & Bangladesh & 15 & $18.0 \%$ & Armenia & 2 & $9.0 \%$ \\
\hline Norway & 183 & $53.9 \%$ & Vietnam & 15 & $42.5 \%$ & Belarus & 2 & $62.9 \%$ \\
\hline Poland & 164 & $39.5 \%$ & Lebanon & 14 & $9.0 \%$ & Montenegro & 2 & $17.4 \%$ \\
\hline Israel & 133 & $50.3 \%$ & Bulgaria & 13 & $23.4 \%$ & Paraguay & 2 & $14.4 \%$ \\
\hline Greece & 132 & $42.5 \%$ & Ecuador & 13 & $15.6 \%$ & UAE & 2 & $12.6 \%$ \\
\hline Denmark & 123 & $63.5 \%$ & Philippines & 12 & $17.4 \%$ & Zimbabwe & 2 & $22.2 \%$ \\
\hline Turkey & 117 & $17.4 \%$ & Costa Rica & 10 & $18.0 \%$ & Bolivia & 1 & $15.0 \%$ \\
\hline South Africa & 113 & $52.1 \%$ & Cyprus & 9 & $38.3 \%$ & Fiji & 1 & $40.7 \%$ \\
\hline Finland & 108 & $28.7 \%$ & Lithuania & 9 & $39.5 \%$ & Kazakhstan & 1 & $17.4 \%$ \\
\hline New Zealand & 108 & $68.9 \%$ & Iceland & 8 & $77.8 \%$ & Mauritius & 1 & $37.7 \%$ \\
\hline Czech Republic & 103 & $44.9 \%$ & Malta & 8 & $15.6 \%$ & Monaco & 1 & $47.9 \%$ \\
\hline Russia & 102 & $68.9 \%$ & Sri Lanka & 8 & $15.6 \%$ & Nepal & 1 & $19.2 \%$ \\
\hline Belgium & 101 & $47.9 \%$ & Ghana & 7 & $45.5 \%$ & Nicaragua & 1 & $92.8 \%$ \\
\hline Korea, DPR & 94 & $52.1 \%$ & Jordan & 7 & $16.8 \%$ & Palestine & 1 & $17.4 \%$ \\
\hline Colombia & 85 & $17.4 \%$ & Kenya & 7 & $17.4 \%$ & Panama & 1 & $15.0 \%$ \\
\hline Ireland & 74 & $15.0 \%$ & Oman & 7 & $16.8 \%$ & Senegal & 1 & $39.5 \%$ \\
\hline Taiwan & 70 & N/A & Tunisia & 7 & $17.4 \%$ & Uzbekistan & 1 & $17.4 \%$ \\
\hline Iran & 67 & $6.0 \%$ & Ukraine & 7 & $15.0 \%$ & Zambia & 1 & $55.7 \%$ \\
\hline
\end{tabular}


Our main source of data for the "Percent Open" variable is the 2021 UNESCO COVID-19 education response dashboard. ${ }^{5}$ To construct the variable, we count the number of days the dataset lists as “Closed due to COVID-19” or “Academic break,” divide by 167 (the total number of days between Jan 1 and July 31, 2020), and subtract from 1 to get the openness measure. For the United States, we use the Center for Global Development database for the number of COVID-19-related school closures through July 1, 2020 as only academic breaks are listed in the UNESCO data. ${ }^{6}$ Finally, the UNESCO database appears to have some errors for Finland, Greece, and South Africa. We use more recent local news sources to correct these. The specific modifications are as follows:

1. According to the UNESCO dataset, Finland's schools were fully closed from 18 March to 14 May, 2020, and had an academic break from 15 May to 12 August, 2020. However, we found news articles stating that Finnish schools fully opened from 14 May to 30 May, 2020 and incorporated this information into our openness measure. ${ }^{7}$

2. According to the UNESCO dataset, Greek schools had an academic break starting on June 16, 2020. However, we found news articles stating that the school year was extended to June 26, 2020, and updated our openness measure to reflect this. ${ }^{8}$

3. According to the UNESCO dataset, South Africa's schools were partially open starting on June 1, 2020 and fully closed before this date. However, we found new articles stating that the government postponed school re-openings until June 8, 2020, and updated our openness measure to reflect this. ${ }^{9}$

Table A.2 shows the gender differences in partner employment measures. Partners of men spent significantly less time daily (over 2 hours less) in paid employment both pre- and post-COVID19. Men are also significantly more likely to have a partner who does not work in paid employment

\footnotetext{
5 Available from http://covid19.uis.unesco.org/global-monitoring-school-closures-covid19. Accessed December 1, 2021. Note that Taiwan is not listed in the UNESCO database, and we therefore omit these respondents from our analysis of school openness. We also omit respondents from Hong Kong due to possible differences between its closure policies and that of mainland China.

6 Available from https://www.cgdev.org/media/covid-19-education-policy-tracker. Accessed December 1, 2021.

7 See https://www.helsinkitimes.fi/finland/finland-news/domestic/17695-thl-schools-will-have-some-coronavirus-cases-but-risk-of-widespread-is-low.html. Accessed December 13, 2021. We thus code Finnish schools as fully closed from 18 March to 13 May, 2020, fully open from 13 May to 30 May, 2020, and on academic break from 31 May to 12 August, 2020.

8 See https://www.thenationalherald.com/greek-primary-schools-kindergartens-will-be-in-session-june-1-26-extending-the-usual-academicyear/. Accessed December 13, 2021.

9 See https://www.africanews.com/2020/06/10/95-percent-of-schools-reopen-in-south-africa-after-virus-lockdown/. Accessed December 13, 2021.
} 
(stay-at-home partner) both pre- and past-pandemic. Since the pandemic, the gender gap in the probability of having a stay-at-home partner has increased significantly (see the last row).

Table A.2: Summary Statistics of Partner Employment Variables, by Gender

\begin{tabular}{lccc}
\hline \hline Variable & Men & Women & t-test p-value \\
\hline Partner Employment (daily hours pre-COVID) & 5.709 & 8.043 & $<0.001$ \\
Partner Employment (daily hours post-COVID) & 4.333 & 6.459 & $<0.001$ \\
Share with Stay-at-Home Partner (pre-COVID) & 0.210 & 0.052 & $<0.001$ \\
Share with Stay-at-Home Partner (post-COVID) & 0.278 & 0.091 & $<0.001$ \\
Change in stay-home probability of partner & 0.068 & 0.039 & $<0.001$ \\
\hline
\end{tabular}




\section{B. Analysis of Other Time Use Variables}

Tables B.1 and B.2 provide estimates of Equation (1) in the paper for the other time use variables. Relative to the pre-pandemic average, we find that both fathers and mothers with a stay-at-home partner increased time spent on other job-related activities, sleep, and other activities relative to those without (Table B.1, Columns 1, 3, and 4). The change in time spent commuting is unaffected by the presence of a stay-at-home partner (Column 2). There was no significant difference in this change between men and women with stay-at-home partners. However, academic mothers had on average larger decreases in commute time, sleep time, and time spent on other activities compared to academic fathers.

Table B.1: Effects of Having a Stay at Home Partner on the Change in Time Use by Gender

\begin{tabular}{lcccc}
\hline \hline Variable & $\Delta$ OtherJob & $\Delta$ Commute & $\Delta$ Sleep & $\Delta$ Other \\
\cline { 2 - 5 } & $(1)$ & $(2)$ & $(3)$ & $(4)$ \\
\hline Female & -0.0813 & $-0.0907^{* * *}$ & $-0.143^{* * *}$ & $-0.104^{* * *}$ \\
& $(0.0548)$ & $(0.0247)$ & $(0.0267)$ & $(0.0400)$ \\
Home Partner & $0.195^{* *}$ & 0.0382 & $0.0976^{* *}$ & $0.176^{* *}$ \\
& $(0.0838)$ & $(0.0383)$ & $(0.0382)$ & $(0.0717)$ \\
Female + Home Partner & -0.0934 & 0.0146 & -0.0286 & -0.0810 \\
& $(0.180)$ & $(0.0815)$ & $(0.0887)$ & $(0.143)$ \\
\hline Dep. Var. Mean & -0.539 & -1.050 & -0.152 & -0.395 \\
R-squared & 0.0276 & 0.0247 & 0.0316 & 0.0262 \\
No. Observations & 5553 & 5553 & 5553 & 5553 \\
\hline
\end{tabular}

Notes: Sample restricted to respondents with youngest child under 12 years of age in the household. Estimates from OLS regressions with controls for $\mathrm{PhD}$ year and date of survey completion FE. Significance levels: ${ }^{*} \mathrm{p}<0.10$; ${ }^{* *} \mathrm{p}<0.05$; ${ }^{* * *} \mathrm{p}<0.01$.

Access to public school is associated with a statistically equal increase in time spent on other job-related activities for mothers and fathers of young children (Table B.2, Column 1). Columns 2 and 3 of Table B.2 indicate that parents in countries where schools were open experienced greater commute times and slept less than parents in countries where schools were closed. School openness does not have a statistically different effect on academic mothers compared to academic fathers on these three dimensions. Finally, Column 4 shows that fathers of young children are more likely to engage in other activities when schools are open than mothers of young children. 
Table B.2: Effects of Primary School Openness on the Change in Time Use by Gender

\begin{tabular}{lcccc}
\hline \hline Variable & $\Delta$ OtherJob & $\Delta$ Commute & $\Delta$ Sleep & $\Delta$ Other \\
\cline { 2 - 5 } & $(1)$ & $(2)$ & $(3)$ & $(4)$ \\
\hline Female & -0.0382 & -0.0326 & $-0.207^{* * *}$ & 0.141 \\
& $(0.142)$ & $(0.0661)$ & $(0.0688)$ & $(0.112)$ \\
Openness & $0.803^{* * *}$ & $0.467^{* * *}$ & $-0.204^{* *}$ & $0.525^{* * *}$ \\
& $(0.201)$ & $(0.0960)$ & $(0.0924)$ & $(0.171)$ \\
Female + Openness & -0.227 & -0.153 & 0.122 & $-0.632^{* * *}$ \\
& $(0.306)$ & $(0.143)$ & $(0.143)$ & $(0.243)$ \\
\hline Dep. Var. Mean & -0.514 & -1.048 & -0.172 & -0.407 \\
R-squared & 0.0290 & 0.0294 & 0.0319 & 0.0241 \\
No. Observations & 5773 & 5773 & 5773 & 5773 \\
\hline
\end{tabular}

Notes: Sample restricted to respondents with youngest child under 12 years of age in the household. Estimates from OLS regressions with controls $\mathrm{PhD}$ year and date of survey completion. Significance levels: ${ }^{*} \mathrm{p}<0.10 ;{ }^{* *} \mathrm{p}<0.05 ;{ }^{* * *} \mathrm{p}<0.01$. 


\section{Additional Specifications and Robustness Checks}

Table C.1 replicates the analysis in Table 1 in the paper, but defines the stay-at-home partner variable as 1 when the respondent's partner had zero hours in paid employment post-COVID-19 and 0 otherwise. We find broadly similar results as with the definition based on pre-COVID employment status. The only difference is that the post-COVID measure indicates that mothers of young children with a stay-at-home partner benefit significantly less in terms of childcare reductions than do fathers with a stay-at-home partner (Column 2).

Table C.1: Effects of Having a Stay at Home Partner PostCOVID on the Change in Time Use by Gender

\begin{tabular}{lccc}
\hline \hline Variable & \multicolumn{3}{c}{$\Delta$ Research $\Delta$ Childcare $\Delta$ Housework } \\
\cline { 2 - 4 } & $(1)$ & $(2)$ & $(3)$ \\
\hline Female & $-0.422^{* * *}$ & $0.679^{* * *}$ & $0.143^{* * *}$ \\
& $(0.0600)$ & $(0.0626)$ & $(0.0294)$ \\
Home Partner & $0.350^{* * *}$ & $-0.866^{* * *}$ & -0.00398 \\
& $(0.0865)$ & $(0.0767)$ & $(0.0396)$ \\
Female + Home Partner & 0.00275 & $0.381^{* *}$ & $-0.281^{* * *}$ \\
& $(0.165)$ & $(0.166)$ & $(0.0771)$ \\
\hline Dep. Var. Mean & -1.576 & 2.903 & 0.809 \\
R-squared & 0.0393 & 0.101 & 0.0264 \\
No. Observations & 5551 & 5551 & 5551 \\
\hline
\end{tabular}

Notes: Partner employment measured post-COVID. Sample restricted to respondents with youngest child under 12 years of age in the household. Estimates from OLS regressions with controls for $\mathrm{PhD}$ year and date of survey completion FE. Significance levels: * $\mathrm{p}<0.10$; ${ }^{* *} \mathrm{p}<0.05 ; * * * \mathrm{p}<0.01$.

Table C. 2 replicates the analysis in Table 1 in the paper, but defines the stay-at-home partner variable as 1 when the respondent's partner worked two or fewer hours in paid employment preCOVID-19 and 0 otherwise. We again find similar results as reported in Table 1 . The only noteworthy difference is that having a stay-at-home partner is now associated with a significant reduction in housework for fathers, but the reduction is still larger for mothers, on average. 
Table C.2: Effects of Having a Stay at Home or Partly Employed Partner on the Change in Time Use by Gender

\begin{tabular}{|c|c|c|c|}
\hline \multirow[t]{2}{*}{ Variable } & $\Delta$ Research & $\Delta$ Childcare & $\Delta$ Housework \\
\hline & (1) & (2) & (3) \\
\hline \multirow[t]{2}{*}{ Female } & $-0.403^{* * *}$ & $0.688 * * *$ & $0.115^{* * *}$ \\
\hline & $(0.0590)$ & $(0.0618)$ & $(0.0291)$ \\
\hline \multirow[t]{2}{*}{ Home Partner } & $0.495 * * *$ & $-0.953^{* * *}$ & $-0.0843^{* *}$ \\
\hline & $(0.0892)$ & $(0.0762)$ & $(0.0395)$ \\
\hline \multirow[t]{2}{*}{ Female + Home Partner } & 0.138 & 0.223 & $-0.214^{* *}$ \\
\hline & $(0.189)$ & $(0.179)$ & $(0.0946)$ \\
\hline Dep. Var. Mean & -1.576 & 2.902 & 0.809 \\
\hline R-squared & 0.0432 & 0.104 & 0.0263 \\
\hline No. Observations & 5553 & 5553 & 5553 \\
\hline
\end{tabular}

Table C.3 replicates the analysis in Table 2 and confirms that the results do not change substantially when we omit respondents from the United States.

\begin{tabular}{|c|c|c|c|}
\hline \multirow[t]{2}{*}{ Variable } & $\Delta$ Research & $\Delta$ Childcare & $\Delta$ Housework \\
\hline & $(1)$ & $(2)$ & (3) \\
\hline \multirow[t]{2}{*}{ Female } & $-0.853^{* * *}$ & $0.804^{* * *}$ & 0.107 \\
\hline & $(0.157)$ & $(0.148)$ & $(0.0762)$ \\
\hline \multirow[t]{2}{*}{ Openness } & 0.221 & $-1.017 * * *$ & $-0.934^{* * *}$ \\
\hline & $(0.222)$ & $(0.204)$ & $(0.103)$ \\
\hline \multirow[t]{2}{*}{ Female + Openness } & $0.685^{* *}$ & -0.0366 & 0.0315 \\
\hline & $(0.327)$ & $(0.330)$ & $(0.151)$ \\
\hline Dep. Var. Mean & -1.478 & 2.656 & 0.836 \\
\hline R-squared & 0.0476 & 0.0840 & 0.0691 \\
\hline No. Observations & 3496 & 3496 & 3496 \\
\hline
\end{tabular}


Tables C.4 and C.5 replicate the analysis in Tables 1 and 2, respectively, for parents with the youngest child in the household younger than 8 years of age. The results are not substantively different, but the magnitudes of the effects increase when we look at younger children.

Table C.4: Effects of Having a Stay at Home Partner on the Change in Time Use (Youngest Child under 8)

\begin{tabular}{|c|c|c|c|}
\hline \multirow[t]{2}{*}{ Variable } & $\Delta$ Research & $\Delta$ Childcare & $\Delta$ Housework \\
\hline & (1) & (2) & (3) \\
\hline \multirow[t]{2}{*}{ Female } & $-0.426^{* * *}$ & $0.771^{* * *}$ & $0.130 * * *$ \\
\hline & $(0.0666)$ & $(0.0715)$ & $(0.0334)$ \\
\hline \multirow[t]{2}{*}{ Home Partner } & $0.563^{* * *}$ & $-1.038 * * *$ & -0.00382 \\
\hline & $(0.108)$ & $(0.0944)$ & $(0.0480)$ \\
\hline \multirow[t]{2}{*}{ Female + Home Partner } & 0.223 & 0.151 & $-0.453 * * *$ \\
\hline & $(0.222)$ & $(0.215)$ & $(0.0948)$ \\
\hline Dep. Var. Mean & -1.751 & 3.197 & 0.815 \\
\hline R-squared & 0.0472 & 0.106 & 0.0354 \\
\hline No. Observations & 4230 & 4230 & 4230 \\
\hline
\end{tabular}

Table C.5: Effects of Primary School Openness on the Change in Time Use (Youngest Child under 8)

\begin{tabular}{|c|c|c|c|}
\hline \multirow[t]{2}{*}{ Variable } & $\Delta$ Research & $\Delta$ Childcare & $\Delta$ Housework \\
\hline & $(1)$ & $(2)$ & (3) \\
\hline \multirow[t]{2}{*}{ Female } & $-0.995 * * *$ & $0.999 * * *$ & 0.125 \\
\hline & $(0.182)$ & $(0.187)$ & $(0.0901)$ \\
\hline \multirow[t]{2}{*}{ Openness } & 0.0620 & $-0.644^{* *}$ & $-0.917 * * *$ \\
\hline & $(0.263)$ & $(0.257)$ & $(0.123)$ \\
\hline \multirow[t]{2}{*}{ Female + Openness } & $1.051^{* * *}$ & -0.0583 & -0.00839 \\
\hline & $(0.387)$ & $(0.414)$ & $(0.185)$ \\
\hline Dep. Var. Mean & -1.764 & 3.240 & 0.805 \\
\hline R-squared & 0.0454 & 0.0840 & 0.0593 \\
\hline No. Observations & 4312 & 4312 & 4312 \\
\hline
\end{tabular}


Finally, Table C.6 reports estimates from a specification where we include both school openness and stay-at-home partner variables and their interactions with gender. The results are not substantively different from when we analyze the influence of each factor separately.

Table C.6: Effects of Having a Stay at Home Partner and Primary School Openness on the Change in Time Use

\begin{tabular}{lccc}
\hline \hline Variable & \multicolumn{2}{c}{$\Delta$ Research } & \multicolumn{2}{c}{ Childcare } & $\Delta$ Housework \\
\cline { 2 - 4 } & $(1)$ & $(2)$ & $(3)$ \\
\hline Female & $-0.773^{* * *}$ & $0.732^{* * *}$ & 0.0976 \\
& $(0.164)$ & $(0.161)$ & $(0.0815)$ \\
Home Partner & $0.500^{* * *}$ & $-0.986^{* * *}$ & -0.0488 \\
& $(0.0999)$ & $(0.0836)$ & $(0.0432)$ \\
Openness & -0.0610 & $-0.625^{* * *}$ & $-1.040^{* * *}$ \\
& $(0.231)$ & $(0.220)$ & $(0.110)$ \\
Female + Home Partner & 0.106 & 0.284 & $-0.245^{* *}$ \\
& $(0.205)$ & $(0.199)$ & $(0.103)$ \\
Female + Openness & $0.841^{* *}$ & -0.0960 & 0.109 \\
& $(0.347)$ & $(0.354)$ & $(0.167)$ \\
\hline Dep. Var. Mean & -1.570 & 2.926 & 0.798 \\
R-squared & 0.0464 & 0.106 & 0.0572 \\
No. Observations & 5093 & 5093 & 5093 \\
\hline
\end{tabular}

Notes: Sample restricted to respondents with youngest child under 12 years of age in the household. Estimates from OLS regressions with controls for $\mathrm{PhD}$ year and date of survey completion FE. Significance levels: ${ }^{*} \mathrm{p}<0.10 ;{ }^{* *} \mathrm{p}<0.05 ;{ }^{* * *} \mathrm{p}<0.01$. 